\title{
The bee sting and the eye: A case report of an ab-externo sting removal technique
}

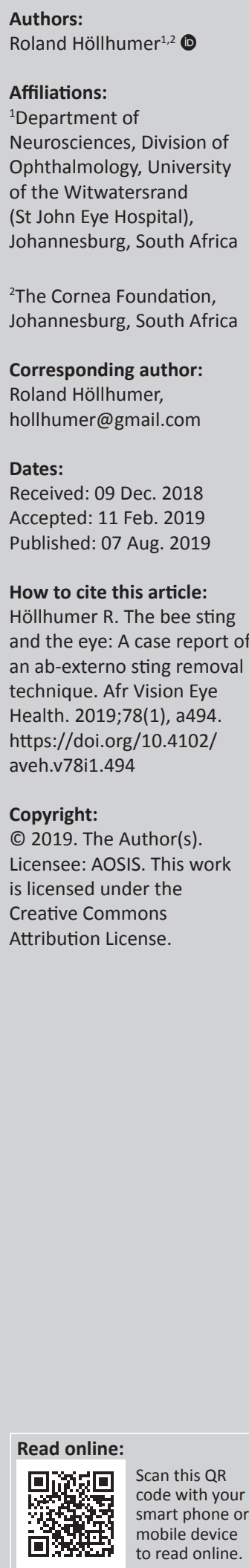

Bee stings are a rare form of ocular trauma with the ocular sequelae attributable to the mechanical effects of the stinger as well as the inflammatory and neurotoxic effects of the venom. This research reports on a case of a retained corneal bee stinger and the technique used for removal of the stinger. This case report is of a patient that presented with a retained corneal bee stinger to St John Eye Hospital, Soweto. A 45-year-old male presented with a retained bee sting in the anterior chamber angle of the eye. A combination ab-externo technique was used to remove the sting. We present the case of a honey bee sting to the cornea that was removed using an ab-externo technique to maintain globe integrity and preserve vision.

Keywords: bee sting; cornea; South Africa; ab-externo; lamellar.

\section{Introduction}

Beestings are a rare form of ocular trauma with a wide array of potential ocular complications that range from mild inflammation to complete visual loss. These have been described most commonly in the cornea and optic nerve but may affect any ocular structure (Table 1). . $, 2,3,4,5,6,7,7,9,10,11$

Ocular sequelae have been attributed to both the mechanical trauma of the sting and the toxic effect of the venom. The venom has inflammatory and neurotoxic components that contribute to the clinical picture..$^{4,10}$ Once the effect of the toxin has worn off, it has been postulated that the sting itself may remain inert in the eye., ${ }^{2,12}$

The sting of a honeybee has a multi-barbed architecture that makes it difficult to remove in one piece, and persistent inflammation has been reported with the incomplete removal of a sting. ${ }^{13,14}$ In many cases, the sting has been removed with a needle; however, where this is not feasible, two alternative methods of removal have been described - linear incision over the sting and the creation of a corneal flap to create access to the sting. ${ }^{1,2,14}$

We report on a combination method to remove a retained bee sting in the sclera by lamellar and linear scleral dissection.

\section{Ethical considerations}

Ethics clearance was obtained from the Human Research Ethics Committee, the University of the Witwatersrand (clearance number M1810101).

\section{Case report}

A 45-year-old male was reviewed at the corneal service at St. John Eye hospital, a week after an insect flew into his right eye. He reported persistent irritation and redness in the eye, which did not respond to topical chloramphenicol ointment prescribed at his local clinic.

On examination, his uncorrected visual acuity was 6/9 in the right eye and 6/6 in the left eye. The right eye had conjunctival infection and limbal inflammation at 8:00 (Figure 1a). With slit lamp examination at $25^{\prime}$ magnification, a bifid protrusion resembling a bee sting was noted in the anterior chamber angle at the area of limbal inflammation (Figure 1b). This was clearly visible on gonioscopy (Figure 1c). The rest of the cornea was clear with a quiet anterior chamber, normal pupillary reflexes, intra-ocular pressure and lens. The vitreous was quiet with a normal appearing optic disc and retina.

The patient was taken to the theatre for removal of the presumed sting under peribulbar anaesthesia with $2 \%$ lignocaine and $0.5 \%$ bupivacaine. A peritomy was formed from 06:00-09:00 and lamellar scleral flap created to identify the base of the sting. A linear incision was made over 
TABLE 1: Ocular complications of a bee sting.

\begin{tabular}{ll}
\hline Ocular structure & Complications \\
\hline Eyelids & $\begin{array}{l}\text { Lid oedema } \\
\text { Retained tarsal sting with corneal abrasion }\end{array}$ \\
Conjunctiva & $\begin{array}{l}\text { Conjunctivitis } \\
\text { Chemosis }\end{array}$ \\
Cornea & Keratitis \\
& Endothelial decompensation \\
& Scarring \\
& Vascularisation \\
Anterior chamber & Anterior uveitis \\
Iris & Hyphaema \\
Lens & Iris atrophy \\
Vitreous & Cataract \\
Retina and choroid & Vitritis \\
Optic nerve & Chorioretinal detachment \\
\hline
\end{tabular}

the length of the sting, which allowed it to be lifted out in one piece with a 27-guage needle (Figure 2). The scleral flap was closed with 10.0 nylon and subconjunctival moxifloxacin and dexamethasone were administered. The patient was kept on topical ciprofloxacin $(0.3 \%)$ and dexamethasone $(0.1 \%)$ for a month after surgery.

The sting was sent to parasitology for analysis and was confirmed to be the sting of a honey bee. On the last followup 5 months after surgery, his visual acuity was $6 / 6$ bilaterally with a clear cornea and normal ocular examination.

\section{Discussion}

We present the case of a honey bee sting to the cornea that was protruding into the anterior chamber angle of the eye. It was removed by a combination ab-externo technique that maintained globe integrity and resulted in full visual recovery.

A bee sting to the eye has two potential sequelae, the first is secondary to the mechanical effects of the barbed sting. ${ }^{4}$ This can result in a foreign body sensation and ocular surface abrasions if embedded in the tarsal plate. ${ }^{5}$ The second is caused by the venom introduced with the sting. The main components of the venom produce inflammation (melittin), neurotoxicity (apamin) and hypersensitivity (phospholipase-A2 and hyaluronidase) reactions. ${ }^{1,13}$ The corneal effects of a sting are therefore related to both elements. Lin et al. ${ }^{10}$ showed that early removal of the sting resulted in rapid resolution of the corneal signs, whereas Arcieri et al. ${ }^{4}$ showed that a sting left in situ in a 12-year-old child had no long-term complications. Our patient was stung a week before presentation and still had a significant amount of conjunctival inflammation at presentation. Removal of the sting resulted in a rapid improvement with visual recovery. Altogether this suggests that removal of the sting is advocated if there is inflammation at the time of presentation.

The most common methods to remove a sting are with a needle at the slit lamp or linear incision over the sting and removal
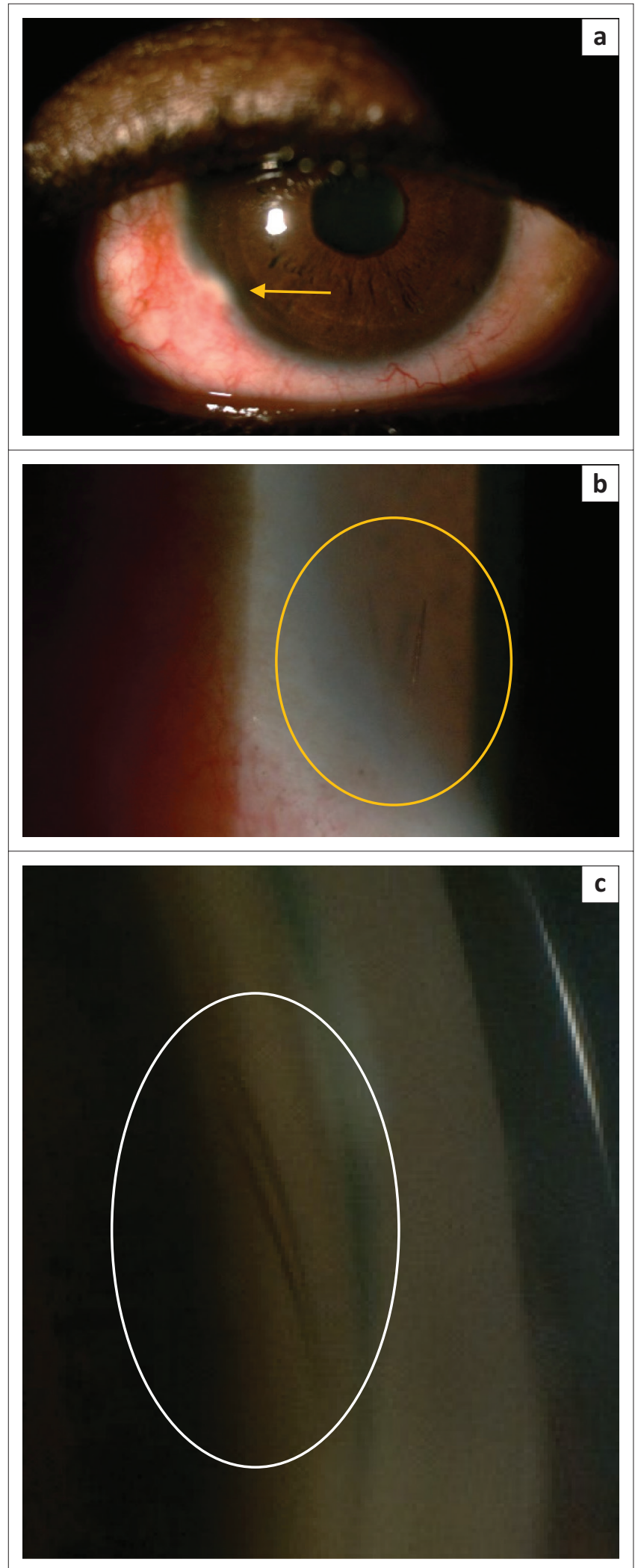

Source: Photos taken by Dr Sarah Ismail

FIGURE 1: (a) Anterior segment photo showing the conjunctival injection and limbal inflammation (yellow arrow). (b) Anterior segment photo with sting projecting into the anterior chamber (yellow circle). (c) Gonioscopy with the sting apparatus visible in the angle (white circle).

with a needle. ${ }^{1,2,3,6,10,11}$ When the sting is too deeply embedded or poorly visible, additional techniques for removal may be employed. Chauhan et al. ${ }^{15}$ described the use of a 20-gauge 

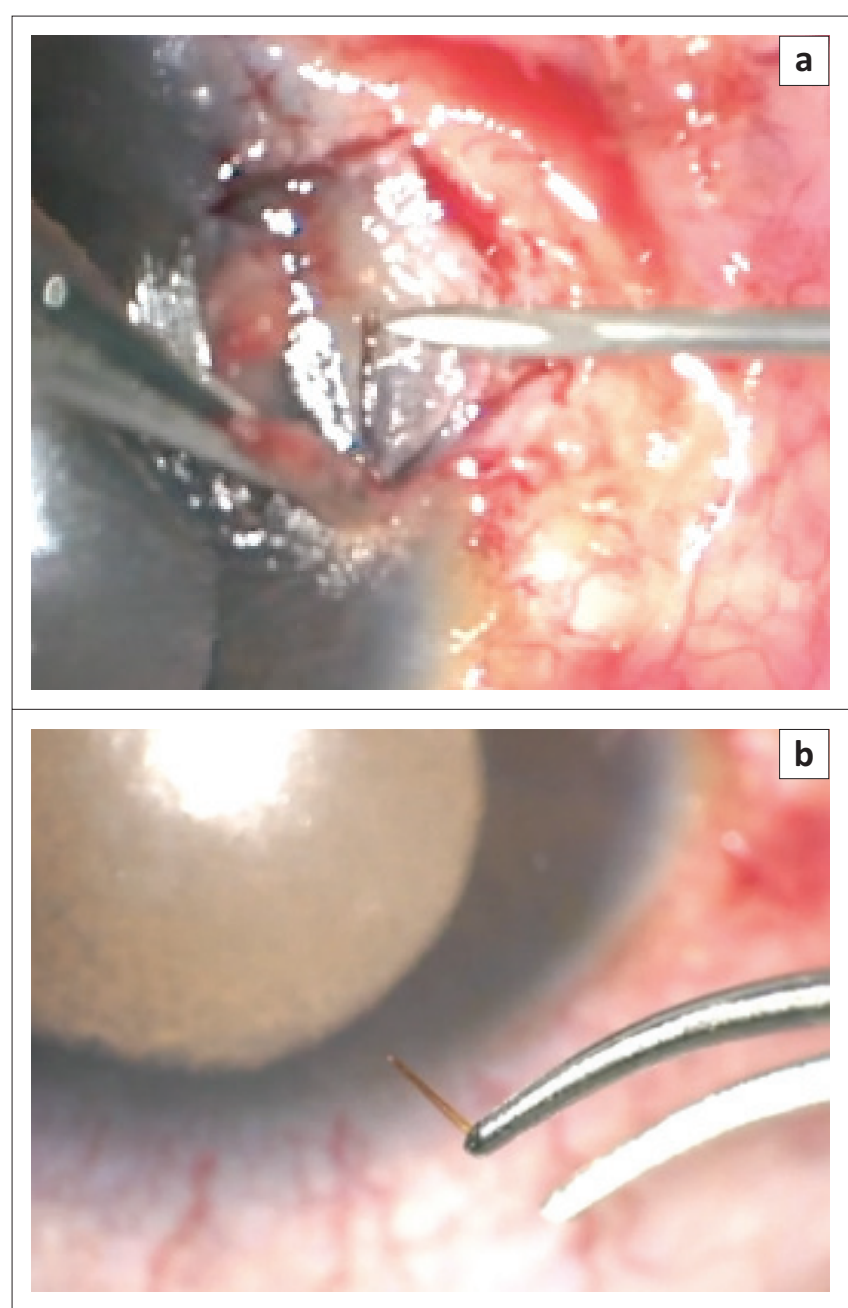

Source: Photos taken by Dr Roland Höllhumer

FIGURE 2: Intraoperative photos showing (a) the lamellar flap and linear incision with sting being removed by a needle and (b) the removed sting.

fibre-optic light source to identify a poorly visible, embedded sting. Jain et al. ${ }^{12}$ described a corneal flap that was used to expose a pre-descemet embedded sting. We employed a combination of techniques to identify and remove the sting in our patient. The scleral lamellar flap allowed us to localise the sting while keeping a closed globe. The linear incision was used to allow removal of the sting in one piece. This is vital as persistent inflammation may occur with retained sting fragments. ${ }^{15}$

We present the case of a honey bee sting to the cornea with a retained sting in the anterior chamber angle. The sting was accessed through a lamellar scleral flap and removed with a $27 \mathrm{G}$ needle. This ab-externo technique maintained globe integrity allowing the patient to recover normal vision.

\section{Acknowledgements}

The author is grateful to Prof. John Frean, associate professor, Parasitology Reference Laboratory, Centre for Emerging, Zoonotic and Parasitic Diseases, National Institute for Communicable Diseases, for identifying the bee sting. The author also thanks Dr Sarah Ismail, Registrar, Ophthalmology, University of the Witwatersrand.

\section{Competing interests}

The author declares that he has no financial or personal relationships that may have inappropriately influenced him in writing this article.

\section{Authors' contributions}

R.H. is the sole author of this article.

\section{Funding information}

This research received no specific grant from any funding agency in the public, commercial or not-for-profit sectors.

\section{Data availability statement}

Data sharing is not applicable to this article.

\section{Disclaimer}

The views and opinions expressed in this article are those of the authors and do not necessarily reflect the official policy or position of any affiliated agency of the authors.

\section{References}

1. Höllhumer R, Carmichael TR. Bee sting of the cornea: A running case report. Afr Vision Eye Health. 2015;74(1):Art. \#288, 1-3. https://doi.org/10.4102/aveh. v74i1.288

2. Razmjoo H, Abtahi M-A, Roomizadeh $P$, et al. Management of corneal bee sting. Clin Ophthalmol. 2011;5:1697-1700. https://doi.org/10.2147/OPTH.S26919

3. Siddharthan KS, Raghavan A, Revathi R. Clinical features and management of ocular lesions after stings by hymenopteran insects. Indian J Ophthalmol. 2014;62(2):248-251. https://doi.org/10.4103/0301-4738.128637

4. Arcieri ES, França ET, De Oliveria $\mathrm{HB}$, et al. Ocular lesions arising after stings by hymenopteran insects. Cornea. 2002;21(3):328-330. https://doi.org/10.1097/ 00003226-200204000-00019

5. Chaurasia S, Muralidhar R. Retained bee sting in the tarsal plate. Int Ophthalmol. 2011;31(2):111-112. https://doi.org/10.1007/s10792-011-9418-z

6. Gudiseva $\mathrm{H}$, Uddaraju $\mathrm{M}$, Pradhan $\mathrm{S}$, et al. Ocular manifestations of isolated corneal bee sting injury, management strategies, and clinical outcomes. Indian J Ophthalmol. 2018;66(2):262-268. https://doi.org/10.4103/ijo.IJO_600_17

7. Maltzman JS, Lee AG, Miller NR. Optic neuropathy occurring after bee and wasp sting. Ophthalmology. 2000;107(1):193-195. https://doi.org/10.1016/S01616420(99)00020-2

8. Pal N, Azad RV, Sharma YR, et al. Bee sting-induced ciliochoroidal detachment. Eye (Lond). 2005;19(9):1025-1026. https://doi.org/10.1038/sj.eye.6701720

9. Rishi E, Rishi P. Intraocular inflammation in a case of bee sting injury. GMS Ophthalmol Cases. 2018;8:Doc02. https://doi.org/10.3205/oc000084

10. Lin $\mathrm{P}-\mathrm{H}$, Wang N-K, Hwang $\mathrm{Y}-\mathrm{S}$, et al. Bee sting of the cornea and conjunctiva: Management and outcomes. Cornea. 2011;30(4):392-394. https://doi.org/ 10.1097/ICO.0b013e3181f234a6

11. Gürlü VP, Erda N. Corneal bee sting-induced endothelial changes. Cornea. 2006;25(8):981-983. https://doi.org/10.1097/01.ico.0000226364.57172.72

12. Jain $\mathrm{V}$, Shome $\mathrm{D}$, Natarajan $\mathrm{S}$. Corneal bee sting misdiagnosed as viral keratitis. Cornea. 2007;26(10):1277-1278. https://doi.org/10.1097/ICO.0b013e31814b 8 bae

13. Brown TC. Reactions to honeybee stings: An allergic prospective. Curr Opin Allergy Clin Immunol. 2013;13(4):365-371. https://doi.org/10.1097/ACI.0b013 e3283625144

14. Yildirim N, Erol N, Basmak H. Bee sting of the cornea: A case report. Cornea. 1998;17(3):333-334.

15. Chauhan D. Corneal honey bee sting: Endoilluminator-assisted removal of retained sting. Int Ophthalmol. 2012;32(3):285-288. https://doi.org/10.1007/ s10792-012-9553-1 